Hybridity, Sociomateriality and Compassion:

\title{
What happens when a river floods and a city's organizations respond?
}

\author{
Ace Volkmann Simpson ${ }^{1 *}$, Miguel Pina e Cunha ${ }^{2}$, Stewart Clegg ${ }^{3}$
}

${ }^{1}$ UTS Business School, University of Technology Sydney (UTS), P.O. Box 123, Broadway NSW 2007, Australia; ace.simpson@uts.edu.au

${ }^{*}$ Corresponding author: P.O. Box 123, Broadway NSW 2007, Australia; Phone: +61 (0) 295143278

${ }^{2}$ Nova School of Business and Economics, Universidade Nova de Lisboa; Campus de Campolide, 1099-032 Lisbon, Portugal; mpc@novasbe.pt

${ }^{3}$ UTS Business School, University of Technology Sydney (UTS), P.O. Box 123, Broadway NSW 2007, Australia, stewart.clegg@,uts.edu.au; Nova School of Business and Economics, Universidade Nova de Lisboa; Campus de Campolide, 1099-032 Lisbon, Portugal; Newcastle University Business School, 5 Barrack Road, Newcastle upon Tyne, NE1 4SE, UK. 


\title{
Hybridity, Sociomateriality and Compassion:
}

\section{What happens when a river floods and a city's organizations respond?}

\author{
Abstract \\ In this study we analyze the ethics of compassionate support provided by \\ organizations to their employees during and after the Brisbane flood crisis of January \\ 2011. The relationship between the social and the material is often taken for granted \\ in discussions of compassion, which has largely been conceived as an emotion or an \\ ethical virtue. By contrast, we see it as a variable state that is contingent on \\ phenomenal events, social relations, organizational routines, technology and \\ corporeality. These are entangled in temporal processes in which the ethics of \\ organizing compassion are constituted. When traumatic events occur processes of \\ sociomateriality can substantiate or negate organizational compassion.
}

\section{Keywords}

Compassion; crisis; ethics; organization studies; social theory; sociomateriality. 


\section{Highlights}

- Sociomaterial relations entail not only human relations but also involve relations with non-human phenomena, especially unexpected events.

- Organizational compassion unfolds in response to such events as a process of serial choices.

- During critical (i.e.: life-threatening) events the ways in which determinate and responsible human agency intervenes to reconfigure sociomateriality becomes judged as more or less ethically compassionate. 


\section{Introduction}

Scholarly appreciation of the value of virtue ethics in organizations has grown rapidly in the past decade (Cameron \& Winn, 2012; Davis et al., 2013; Rego, Cunha, \& Clegg, 2012) with particular emphasis being given to the ethics of organizational compassion (Kanov et al., 2004; Lilius, Kanov, Dutton, Worline, \& Maitlis, 2012; White, 1999).These scholars argue that compassion entails more than merely an internal psychological disposition or social ethical imperative. A giver and a receiver are necessary for the unfolding of compassion relations but these always occur in a social context. It is the context that provides cues for compassion or for interpretation of its absence, deviance or decline (Berlant, 2004; Nussbaum, 2003; Simpson, Clegg, Lopez, et al., 2014; Simpson, Clegg, \& Pitsis, 2014b).

In this paper we further develop theorizing on organizational compassion by arguing from a sociomaterial perspective that ethical agency in organizational compassion relations resides not just in human actors. Rather, natural phenomena, physical resources, organizational processes and routines, technology and intercorporeality also have an ethical materiality: "Sociomaterial perspectives not only question the acceptance of differential categories such as individual/organization and binaries of subject/object, knower/known etc., but also challenge the givenness of fundamental distinctions between human and non-human" (Fenwick, 2010, p. 107). We discuss organizational compassion relations within the context of a recent tradition of analysis in which the human is not privileged. Significant scholars in this tradition, such as Pickering $(1995,2008)$, draw upon Deleuze $(1990,1994 ; 1988)$, to argue that no innate dualism resides in the relation between people and other entities in the world. Agency is attributable to non-human phenomena just as much to those 
species-beings that speak and act: it also inheres in material objects. In a similar tradition Curtis's (2008, p. 113), analysis of Hurricane Katrina in New Orleans as a sociomaterial phenomenon, is also critical of dominant perspectives that invoke a “restrictive dualism between 'man' (organization) and 'nature' (disorganization)”. He further critiques the "anthropocentric moral framework" in which human action is viewed in terms of good or evil and natural phenomenon is seen as morally neutral. We build upon these ideas to argue that compassion relations are mutually constituted through human-material configurations (van der Velden, 2009) and materialized through "temporally emergent constitutive entanglement" (Orlikowski \& Scott, 2009, p. 547).

Events comprise many phenomenal types: hurricanes, such as Hurricane Katrina that wrought devastation on New Orleans (Curtis, 2008; Frickel \& Vincent, 2007; Piotrowski, 2006); tsunamis, such as that which devastated much of Asia in 2004 (Perry, 2007); terrorists flying high-jacked planes into some of the world's highest and most famous buildings in New York in 2001 (Beunza \& Stark, 2004, 2005). The setting for our study is a specific event: a flood that inundated the City of Brisbane $\left(27^{\circ} 30^{\prime} \mathrm{S}, 153^{\circ} 1^{\prime} \mathrm{E}\right)$, the state capital of Queensland, Australia, in January 2011, which caused the evacuation of the Central Business District (CBD) and surrounding suburbs in the City of Brisbane (Bohensky \& Leitch, 2014; Holmes, 2011; van den Honert \& McAneney, 2011).

We argue that events such as floods possess agency and temporality: they punctuate the ordering of elapsed time. ${ }^{4}$ Linstead and Thanem (2007, p. 1493) describe events as sticking out from the mundane as "a discontinuity in history" that opens up future

\footnotetext{
${ }^{4}$ Think, for example, of the ways in which people divide time into 'before' and 'after' the GFC, 9/11, or the birth of Christ.
} 
possibility "promising further differentiation". Deroy and Clegg (2011, p. 637) further develop these ideas arguing that events, construed as phenomena that "are non-routine", by definition "remain outside the application of a pre-existing rule and this is why they challenge ethics." Events offer potential spaces for action in the study of ethical agency and compassion relations within organisations; they breach the normalcy of routines by providing opportunities for re-imagining what has become tacit and taken-for-granted, not even contemplated in everyday organizational life and thought. Human agents engage in a collective struggle for survival, reassurance and meaning making the framing of which is always threatened by events. Events have material consequences. While there are many kinds of events that one might focus on, catastrophic events have a particular potency because of the destruction and havoc that they can wreak on complex organizational networks, operations and the lives of employees. Complex organizational networks are sociomaterial (Jarzabkowski, Spee, \& Smets, 2013). When people act in organizational roles they do so with the aid of materials, such as the copper wire on which systems of voice and data communication depend, reliant on materialities that lace together social relations, physical structures, and organizational processes.

Events form one coordinate of our account while organizations and their networks provide another. What connects them is the sociomaterial infrastructure. The "sociomaterial approach challenges the deeply taken-for-granted assumption that technology, work, and organizations should be conceptualized separately and advances the view that there is an inherent inseparability between the technical and the social" (Orlikowski \& Scott, 2009, p. 434). Various material media of communication vary in speed and tone when processing exchanges, constituting inter-corporeal, inter-organizational and organizational relations. The entanglement 
of the social with the material ensures that sociomateriality is experienced as an undifferentiated phenomenological continuum where all beings/things are interconnected through overlapping processes. Our focus is on what happens to the human capacity to exert ethical choice when the materiality that ties events, organizations and networks together is severely disrupted. These threads are connected in dynamic sociomaterial interactions that constitute, enable and constrain modes of being not only of human actors but also of events and things. When faced with traumatic and extraordinary events any organizational response, as well as responses to these by individuals, are instances of ethical agency. Following van der Valden $(2009$, p. 38) we define ethical agency as "the capability to act responsibly toward the 'other', in particular to do no harm." During times of crisis a growing body of literature suggests that organizational recognition and responses to employee suffering are important. Responding with care and compassion helps facilitate employee healing and wellbeing (Dutton, Frost, Worline, Lilius, \& Kanov, 2002) as well as job satisfaction, organizational commitment and bonding with fellow employees (Lilius et al., 2008). On the other hand, perceived neglect of employee suffering at times of crisis can lead to feelings of resentment and anger (Dutton et al., 2002). Current theorizing, however, tends towards a methodological individualism, limiting ethical agency to human actors.

We structure this article by first providing a review of the literature on compassionate organizational crisis responding. Second, we introduce our research methods and context: the Brisbane Floods of January 2011. Our central research question is: What are the sociomaterial processes that constitute organizational compassion relations in times of crisis? We address this question through data on organizational responses provided to employees as support during the Brisbane 
floods. We organize our findings in terms of the unfolding processes of compassion responding to an event and its material consequences, involving communication technologies, media reporting, and the policy implications of resource accessibility, tangibles, supporting others and reconnecting . Characteristic of each of these processes is their various configurations of sociomateriality. We conclude by discussing the ethical implications of a sociomaterial view.

\section{Constituting Organizational Compassion as Sociomaterial Practice}

Interest in organizational compassion in the face of suffering emerged in the late 1990s and has been growing over the past decade (Dutton, Workman, \& Hardin, 2014; Lilius et al., 2012; Rynes, Bartunek, Dutton, \& Margolis, 2012; Simpson, Clegg, \& Pitsis, 2014a). Suffering for people in organizations can be triggered by any event deemed traumatic such as a disaster, illness or injury, or other personal tragedies, including a violent attack, the death of a colleague or loved one, or poor social relations (Dutton, Worline, Frost, \& Lilius, 2006; Kanov et al., 2004). The cost of individual human suffering in organizations may include loss of work confidence, loss of self-esteem and health, as well as toxic relations, reduced employee cooperation, as well as disengagement and low commitment (Frost, 1999). Solomon (1998) argues that due to the ever-present potential for human suffering in organizations, compassion and care towards others are requirements and expectations of most employment positions.

Burdenski and Dunson (1999) argue that compassion must be the basis for ethical decision-making. Collective suffering that occurs when normalcy is transgressed violently by whatever mechanism offers an opportunity for ethical decision-making. The ways in which collective employee suffering is responded to and staged in 
organizational arenas is one of the key ways in which the ethicality of decisionmaking is demonstrated - or not. Prior literature has focused on compassion relations as largely a matter of emotional work and repair that is either embedded in specific roles, such as 'toxic handlers' (Frost \& Robinson, 1999), emotional laborers (Hochschild, 1979, 1983), or in specific routines (Ashforth \& Humphreys, 1993). Research finds that organizational compassion can involve small non-routine gestures aimed at alleviating another's distress, which have a big impact for those involved individually and institutionally. Such gestures include giving a get well card, offering an open ear or a kind word, covering a shift for an ill or overwhelmed colleague, 'passing around a hat' to provide financial support to a colleague in dire circumstances, offering an employee special work consideration, or simply giving a colleague a hug or a shoulder to lean on as a holding space for their pain (Frost, Dutton, Worline, \& Wilson, 2000; Lilius, Worline, Dutton, Kanov, \& Maitlis, 2011; Lilius et al., 2008). The individual and institutional benefits of such acts of compassion within organizations are manifold. They include, enhanced positive emotions, organizational commitment, identification and attachment (Lilius et al., 2011; Rhee, Dutton, \& Bagozzi, 2007); emotional sensitivity; resources of organizational pride, trust, motivation and connection; as well as strengthened values of dignity and respect (Dutton, Lilius, \& Kanov, 2007). According to Lawrence and Maitlis (2012) an organizational 'ethic of care' where continuing support is provided in times of normalcy is more desirable than responding with compassion in times of crisis.

Consideration of sociomateriality in current organizational compassion theorizing is non-existent. Although the influence of social contextual factors has been acknowledged, it doesn't go far enough. For example, compassion research findings 
have indicated the importance of routines denoting open organizational architecture, facilitating alertness to suffering, such as holding regular meetings (Kanov et al., 2004; Lilius et al., 2008) as well as creating formal roles and programs that facilitate recognition and response to suffering (Lilius et al., 2012). Other factors that research has indicated as important include the provision of contingencies for addressing emergencies, caring leadership, and internal newsletters for spreading news of care (Dutton et al., 2007). Most significant to the argument of this paper, Dutton et al. (2006) have referred to structuration theory (Giddens, 1982, 1984), to "propose that the process of compassion organizing unfolds through the complex interaction of social architecture and human agency over time" (Dutton et al., 2006, p. 74). Herein, social architecture is described as "the amalgam of social networks, values, and routines that structure an organization" (Dutton et al., 2006, p. 74). While we appreciate that this theorization takes organizational compassion beyond the psychological or emotional domain of analysis, we nonetheless only partially agree with it. In advocating a sociomaterial perspective of organizational compassion, we additionally hold other factors equally significant. We argue that organizational compassion socio-materializes temporally through interactions between natural phenomena or events, human behavior, technology, as well as organizational processes and routines.

For our research, rather than investigate organizations' considered compassion practices and processes, we address naturally occurring situations of organizational breaching - situations that by their eventful and unpredictable nature disrupt preexisting organizational routines. They function as naturally occurring ethnomethodological breaching experiments of normal organizational sensemaking (Garfinkel, 1967). When unscripted and unexpected disaster strikes collectively, the 
ways in which organizations respond demonstrates the compassion (or lack of it) inherent in their practices and significantly punctuates the lived experience of those who are employed by them. Cyclonic or dam waters that flood human habitats are one such unexpected event; not only do they have extreme ecological effects but they also have organizational and embodied effects. People drown, homes are lost, possessions trashed, organizations become inaccessible and sensemaking is disrupted, while not only lives but also organizations are reshaped by the event. Organizations that are inundated, destroyed, or otherwise damaged, in which employees' lives and wellbeing are threatened, are not 'normal' organizations, secure in their routines. Such events manifest themselves in their impact on humans in a fundamentally corporeal manner as the cause of heightened symptoms of physical stress to which a possible but by no means necessary response is one of compassionate support.

\section{Research Context and Method}

'Natural disaster' is pregnant with 'social' possibilities as meaning and materiality is transformed by the event (Henke, 2007). At the most fundamental level, such events destabilize embodied relations to surrounding materialities of possessions, practices and possibilities. In this paper we will focus on one such event: the organizational and management effects of the inundation of the City of Brisbane as a result of severe cyclonic rain - a major rainfall event - having a significant impact on a dam upstream from the major river that ran through the center of the city, which was already filled to overflowing before the extraordinary rain event. An extraordinary rainfall event may be defined as one that, statistically, is of such intensity that it should occur only once in a hundred years. When such an event occurs in a heavily urban sub-tropical climate with a major river running through it - 
and through major urban centers, an accident is highly probable as normal organization and their networks are sundered, broken or damaged in some way.

A river whose upper reaches are contained as a reservoir behind high dam walls that experiences unusually high rainfall, creates: 1) a system that is complex, 2) tightly-coupled with human judgment, and 3) catastrophic in its potential - all the necessary conditions for what Perrow (2011) describes as 'normal accidents' where accidents are bound to happen. Hydrologists commissioned by the Insurance Council of Australia to investigate the 2011 Brisbane River floods concluded that the event was a "dam release flood" (van den Honert \& McAneney, 2011). The Wivenhoe Dam was built upstream from the City of Brisbane to mitigate the threat of flooding in the Brisbane River Catchment after the devastating Brisbane floods of 1974. The dam is also the major source of water supply to the city and much of drought prone South East Queensland. Consequently, engineers operating the dam have to balance two contradictory objectives: keeping the dam water levels as low as possible as a buffer against flooding, and keeping the dam full to ensure water supply as a buffer against low rainfall and drought(van den Honert \& McAneney, 2011). To guide these decisions weather-modeling forecasts are referenced, as are the dam levels themselves. Despite forecasts indicating further rainfall, dam operators, having lived through drought for much of the previous decade ignored the forecasts and operated on a "no further rainfall scenario". Yet, by January 2011, the engineers could no longer ignore the unprecedented and torrential rainfall, as they now perceived the water as being above the dam's capacity and risk parameters. With the release of excess capacity from the Wivenhoe Dam into the Brisbane River as a precaution against the risk of collapse, water began flooding low-lying areas of the state capital of Brisbane on the morning of January 11, 2011. At 2:30 pm the Brisbane River 
broke its banks and at the City Council ordered the evacuation of the CBD and other suburbs: across the Brisbane metropolitan area 14,100 properties were inundated, including 1,203 houses and 2,436 business premises (Holmes, 2011). Statewide the effects were much greater with 23 people drowning, 28,000 homes needing to be rebuilt, 19,000 kilometers of damaged roads, 28 per cent of the rail network in disrepair, 3,570 business premises inundated (van den Honert \& McAneney, 2011), and 58,463 insurance claims worth $\$ 2.4$ billion were lodged (Insurance Council of Australia, 2011). The Queensland Reconstruction Authority estimated the overall cost of the floods to be $\$ 5$ billion (Holmes, 2011) - making it “Australia's most expensive natural disaster in history" (Bohensky \& Leitch, 2014, p. 475). In such a situation ethical choices are inescapable. Choices are implicit in the decisions made by the engineers: should they create a flood as a 'natural disaster', albeit one more hybrid than natural? Having decided to release water the hybrid flood also creates ethical dilemmas for organizational actors downstream who may seek to carry on regardless of the event or seek to respond to it more or less positively in terms of relations with employees.

To investigate how the event of the release of the flood water had significant impact on organizational compassion relations we collected data for this study nine months after the summer floods devastated the city, using a snowball sampling method by accessing established social networks to contact people whose work had been affected during the floods. Ultimately we formed a sample of 25 participants from 18 organizations. Most interviewees worked in the central Brisbane area affected by the floods and had been ordered to evacuate their work areas on January 11. Each of the semi-structured interviews lasted between 20 minutes and an hour. Interviewees were asked to describe their experiences on the day of the floods and 
how it affected their ability to work, their communication with their workplace through the flood, and the types of support their organization provided to employees during and after the floods. Most interviewees responded in narrative form, by telling their personal account of the flood events as they unfolded. The interview process was thereby one of collecting narratives concerning the interviewees' experiences of organizational care or neglect during the floods. A total of 12 hours of interviews were digitally recorded.

The interview data was analyzed following standard procedures and techniques for building grounded theory (Glaser \& Strauss, 1967; Strauss \& Corbin, 1997). Initially complete transcriptions of each interview were imported into Nvivo9, a software package for qualitative research. Then over a period of some 400 hours, the narratives were coded according to key themes and subthemes. Comparison of the narratives provided insight into effects of different contextual variables in the narratives, such as organizational values, beliefs, and support systems (Czarniawska, 2000;

Czarniawska-Joerges, 2004). Setting the various narratives against each other disclosed patterns of similarity and difference revealing a number of processes through which organizational compassion responding materialized during the flood.

While we could have used the data illustratively, as descriptive material, we further interrogated our data to explore general themes relating to socio-temporal processes of emergence. The reconfiguring of social and material objects in time is fundamental in sociomaterial processes of becoming (Orlikowski \& Scott, 2009; Pickering, 1995). We therefore further analyzed our narrative data chronologically to reveal the temporal unfolding of the processes that supported compassion responding during the flood event. Our approach is inspired by sequence analysis, a form of 
research used for assessing the unfolding of events in a narrative (Anheier \& Katz, 2006; Griffin, 1993). The essential concern of sequence analysis is the emergence of phenomena within a specific temporal and spatial social context as "an ordered list of elements" (Abbott, 1995, p. 94). Examples of social research that uses sequence analysis include studies on the successive steps in ritual dance performances (Abbott \& Forrest, 1986), the stages in a career path (Abbott \& Hrycak, 1990; Blair-Loy, 1999; Chan, 1995), the patterns in folktales (Forrest \& Abbott, 1990), the rhetorical structure of sociological articles (Abbott \& Barman, 1997), as well as the study of development sequences in organizational information systems (Sabherwal \& Robey, 1993, 1995).

The critical identifying characteristic of sequences is their ordered nature (Abbott \& Tsay, 2000). We suggest that temporal unfolding also matters in the management of organizational crises such as a major flood event and responses to its flows. We therefore coded our data according to the order of processes interviewees described as they recounted their experience of the unfolding of the flood event. As there is a tendency for repetition in conversation, we only coded the first time each event was mentioned into the dataset, omitting further references. Where a particular event was not mentioned in the interview, it was not coded into the dataset. While the word sequence would suggest that the different processes unfold clearly one after another, we acknowledge that our data represents the retrospective sensemaking and 'processordering' of the interviewees, rather than necessarily the sequential order of 'what actually happened'. The latter could only be accessible through some kind of longitudinal study observing in real-time the events as they unfolded. Our primary interest is in the sociomaterial emergence of the phenomena organizational compassion within the specific temporal and spatial context of the Brisbane Floods. 
Hence, while the general sequential patterns of temporality revealed by our data is of scholarly interest, it is not the primary concern.

A further level of analysis involved analyzing variability within the processes interviewees described. Abbott (1995) explains that sequences need not be one dimensional in nature, they can be dependent upon other internal (within sequence) or external (outside of sequence) variables for their completion. Although there was general consistency in the overall sequence of processes we uncovered, variability was also found within the quality of these processes. Consequently, we further coded subcategories of processes relating to the quality of compassionate care provided within each process as described by the interviewees. These were coded as high quality (3), medium quality (2), and low quality (1).

\section{Findings: Compassion Responding as Six Processes of Sociomateriality}

Analysis of our data on organizational compassion responses in the Brisbane floods revealed six general sociomaterial processes in the unfolding event: (1) communication practices and technologies, (2) the effects of media reporting, (3) confronting issues relating to policy and access to resources, (4) the providing of tangible support by organizations, (5) employees supporting others and (6), employees reconnecting with each other (Table 1). ${ }^{5}$ We acknowledge overlap between the processes; abstracting rich narrative data into simple generalizable processes as a foundation for grand theorizing poses different tradeoffs (Langley, 1999), where the presence or absence of overlap and interrelatedness in the

\footnotetext{
${ }^{5}$ The alphanumeric codes for the events were: communication, coded as C; policy and access to resources, coded as P; tangible support, coded as T; supporting others, coded as S; and reconnecting, coded as R. Each of the events was further coded according to high, medium, or low quality. For example high quality communication was coded as $\mathrm{C} 3$, medium level as $\mathrm{C} 2$, and low level communication as C1. Similarly, high-level policy and resource access was coded as P3, mid level as $\mathrm{P} 2$, and low level as P1.
} 
explanations depends upon the level of abstraction (Weick \& Westley, 1999). As Lynchnell (2011, p. 95) observes "when abstracting the events and analyzing them separately, there is always a risk that the analysis of events decouple from the empirical material... where complex processes are reduced to their lowest common denominator; [and] what remains are sequences of objectively-coded events". Conversely, insisting on the uniqueness of each individual's experience and ignoring the general patterns of similarity found in the data is also a limiting approach to research. We therefore attempt to capture some complexity and variability in our data by also accounting for the significance of each event as described by the participants. Consequently, Table 1 not only indicates the general order of the unfolding of the six processes in the flood event but also the significance and quality of the respective processes within each narrative. All of the 25 interviews discussed communication, indicating that it was the most significant process. For some the communication was poor (low quality) while for others it was exceptional (high quality). Other significant concerns related to policy and resource issues, discussed by 19 interviewees and tangible support, discussed by 22 interviewees. In contrast, efforts to support others were described by only 12 interviewees while 9 discussed reconnecting.

\section{TABLE 1 ABOUT HERE}

\section{First Process in the Unfolding Event: Organizational Communication}

The first process of compassion responding was organizational communication, which was temporally most significant in the pre- and initial-unfolding stages of the flood event. Coombs (1999) and Veil et al. (2011) emphasize the importance during a crisis of compassionate organizational communication, expressed through a caring voice and an empathetic awareness of stakeholder concerns, using a variety of 
communication channels. Communication emerged as an underlying factor expressing or inhibiting compassionate support. Theorists such as Orlikowski (1992, 2007, 2008, 2010) and Suchman (2007) have emphasized the constitutive entanglement of technology with social dimensions in contemporary organizing in various sociomaterial configurations. In the Brisbane floods communication technologies were used temporally, before, during, and after the flood event to communicate with employees: some instances communicated sensemaking (Marshall \& Rollinson, 2004; Weick, 1995) and compassion, while others signified confusion or neglect. A variety of media, including phone, text, and the Internet, were used. The materiality of communication in terms of its immediacy was important. Our data indicates a continuum in speed of compassionate communication. At one end, there was communication that was quick, seeking to express care and concern alleviated the receiver's potential distress. At the other end, there was communication that was slow, which increased the receiver's anxiety. There was a direct connection between the materiality of the communication and the embodied response of the employees. Virtual, immediate communication lessened physical apprehension and anxiety; waiting for more materially slow forms of communication heightened these responses.

As in other crises (Beunza \& Stark, 2005), phone, text, and email messages were vital modes of socio-technology used to communicate work expectations, inquire about employee wellbeing, and provide support. On the day of the Brisbane floods those organizations that displayed a high capability for compassion provided support over the phone, ensuring that all employees had reached home safely, buttressed by supportive text messages. In contrast, in organizations characterized as having a low capability for compassion, employees were either neglected and found out about the 
flood from other sources before going home or received text messages ordering that they had "no excuses" for not coming to work.

In some organizations, social media was used to provide support for and between employees during the flood. A team leader in a Queensland Government department, created a Facebook page to facilitate the provision of support among her team members. She sent text messages, emails, and made phone calls, requesting her supervisees to share information updating others within the team about their welfare and the wellbeing of other team members without Internet access. Students at one of Australia's leading universities were also encouraged to engage with social media such as Facebook and Twitter to network with and support their mentees and peers.

Organizations also used their websites to communicate. In one Brisbane university, Student Support Services used the university website homepage to communicate with students, particularly with those made homeless by the floods inundating either their homes or their means of access to them. The worst affected students were advised to take advantage of the shelters provided by the City Council for food and clothing. International students were additionally offered information on arrangements that had been made for temporary accommodation. The university also used the home page to provide more general information relevant to all students, including updates about adjusted class schedules. The use of the university website to communicate flood information is a good example of how organizations activated sociomaterial possibilities, using technologies to fit the unique circumstances of the flood.

According to Silverman (2006) it is sometimes the few or even single 'deviant' cases that provide the most important and interesting findings in qualitative research. 
As visible in Table 1, organizational communication was the most significant initial compassion responding process for 17 of our 25 interviewees. For six others, the most significant initial event was learning of the flood situation through the media. For one respondent (Table 1, participant 10) the most significant initial event discussed in the interview was providing support to others. Whereas for another (participant 21) the first event discussed was policies and gaining access to resources. Interestingly, it turns out that participants 10 and 21 were higher-level managers with responsibility for many others within large organizations. In other words, for general employees or middle level managers the most significant initial process in organizational compassion responding during crisis is internal communication or learning of the event from the media; for some higher-level managers, however, compassion responses began with considerations of policy and getting support to others. Too much cannot be made of this, however, as there were six other managers in our dataset for whom the materialization of compassion responding also began with communication. A moderating factor might be the manager's position in the organizational hierarchy and their level of empowerment as an independent decisionmaker.

\section{Second Process in the Unfolding Event: Media Communications}

Media and politicians played an important sensemaking role during the floods. Drawing upon Weick (1995, 2003; 1993) Mills and Weatherbee (2006) demonstrate how initial organizational responses to the non-routine and unexpected in disasters can themselves be 'disastrous'. They further highlight how an initial absence of interorganizational sensemaking gradually evolves to an inter-organizational sensemaking convergence - generally framed around the sensemaking of the most powerful 
participants. The Brisbane flood event presents a prime example of such initial divergence and later convergence of sensemaking. As the flood unfolded people turned to the media to make sense of the event. Whereas most described their engagement with the media reporting of the flood in neutral terms, as simply a source of information, some observed that the initial media coverage created a sense of panic. Tragic images of homes flooding and cars washing away were played incessantly over the airways, adding to people's worst fears. While the media aired sensational and tragic images both nationally and internationally, there were initially no positive messages, such as information on what Brisbane residents could do for support, shelter, or for getting home, as some respondents noted. News values were more focused on the spectacular elements of the event in its early stages than they were on the communication of positive measures responding to what was unfolding. Several respondents described receiving calls from their families from overseas countries concerned for the safety in the Brisbane floods. Universities also received calls from concerned parents who had sent, or had been planning to send their children to Brisbane as international students at the beginning of the new academic year, some of whom withdrew their children from the universities.

Prompted by the initial media coverage, a group of representatives from various universities and the City Council, as well as business leaders, worked together to get more positive messages on the airwaves. Their focus was on communicating inspiring human stories of survival, compassion, and community spirit emerging amidst the destruction of the floods. Positive messages instill hope and a drive for action whereas negative ones spread panic and feelings of anomie. The media's broadcasting of more positive messages of support and survival encouraged others to pitch in. As an example, Channel 7's Sunrise breakfast television program initiated 
'Operation Bounce Back' in partnership with the Queensland government (Carah \& Louw, 2012). The television program called upon skilled tradespeople to volunteer in the rebuilding effort and subsequently featured tradespeople doing just that. Journalists and politicians thereby cooperated to coordinate specific representations of the flood event in relationships of mutual dependence, each legitimizing the roles of other in managing impressions of the flood.

According to an interviewee employed by an international travel agency, the positive messages from the media, subsequent to the initial coverage, prompted his organization gradually to improve its efforts in supporting employees during the floods. As he saw it, the media created a context in which competition to be seen as a part of a good news story escalated positive commitments. Hence we see the evolution of such inter-organizational sensemaking during the Brisbane floods as a process of sociomaterialization wherein individuals, organizations, and digital media technology concertedly surmount the constrains of temporal-space to constitute mass social consciousness (Grace \& Fonseca, 2014; Olofsson, 2010) that influenced individual actions, organizational policy and resource availability.

\section{Third Process in the Unfolding Event: Policy Issues and Resource Availability}

Policy issues and resource availability became increasingly significant in the initial stages of the flood as organizations rushed, failed, or in some cases scrambled, to initiate a response. Resources are typically taken to define the capabilities that organizations can access (Wernerfelt, 2006). Resource utilization is normally circumscribed by considerable regulation by policies. As events unfold, however, as Fineman (2004) suggests, the meaning of resources is dynamically altered through their use (or absence) in responding to the temporally unfolding event. Consistent 
with such views, in this study there were instances where bureaucratic procedures and established modes of practice posed a barrier to providing resources for compassionate support in response to the crisis. Consequently, creating exceptions to rules and bending bureaucracy became crucial hallmarks of moral decision-making in terms of compassionate responding. Ordinarily, of course, violation of rules would be perceived as being morally deficient. In some instances it was only after leaders reportedly disrupted norms by providing exceptional support that others felt authorized to make similar adjustments in terms of norms and access to resources. It was then that active compassion responding gained momentum.

Limited access to resources and bureaucracy impeded support. For example, a university employee who tried to communicate emergency information to floodaffected students via the home page of the university website was delayed because she didn't have the necessary authorization. In some organizations bureaucracy was bent in order to provide care. As an example, one interviewee explained that the international software firm in which they work had a workplace relations agreement whereby the organization reserved the right to stand down the entire workforce without pay in times of disaster. During the Brisbane floods not only was this right not exercised but also, the day before the rest of the city evacuated, employees were told to work from home if they could. They were further advised that they would be paid regardless. Such a response contrasts with the experiences of other interviewees who were informed that they would not be paid for the time that they couldn't work during the flood.

It is worth noting that those organizations that provided compassionate responses to their employees during the flood were normally characterized by compassionate 
people-centric policies and practices that were situated outside of the flood context. These included having a philosophy of care, a culture of empowerment and trust, leaders who were caring role models, provision of flexible work arrangements tailored to suit the work/life balance needs of the individual, prior contingency planning for emergencies, and an organizational emphasis on social responsibility. A conclusion that can be drawn from this finding is that organizational compassion materializes most effectively when it is an embedded process residing in dispositional and systemic organizational practices rather than an episodic response to a moment of crisis. Such organizations embodied an 'ethic of care' (Lawrence \& Maitlis, 2012) as a part of their normal mode of being rational.

\section{Fourth Process in the Unfolding Event: Tangible Support}

The fourth temporal process of compassions' socio-materialization was the provision of tangible support both during and after the flood. During the flood this occurred by providing food, shelter, and medical attention, while after the flood it consisted of helping with repairs and cleaning and the provision of financial grants and gifts as well as offers of in-kind goods. Resources such as food, shelter and finance are socially constituted through conjoined social and material relations: "bodies, clothes, food, devices, tools ... are produced through human practices" (Orlikowski 2007, p. 1438). As she goes on to say, the distinction between humans and artifacts is analytical; in practice "these entities relationally entail or enact each other." As the flood heightened some organizations responded by assuring employees unable to work during the flood that they would be paid in full. In other organizations employees were not only paid but also provided with financial gifts to help recover household items that the floods had damaged or destroyed. As an example, when a 
manager inquired about what one of his employees had lost in the flood, the employee explained that she had not been able to save any of her husband's tools from the garage, including the power tools and lawnmower. At a company social evening some days later, the employee was publicly given $\$ 2000$ worth of hardware store vouchers by her manager to replace her husband's work equipment. The employee was appreciative that her manager had taken the time listen to her needs and provided a gift directly related to her flood losses. While on stage receiving the voucher from the manager, the employee gave her manager a hug of gratitude, when he whispered into her ear that an additional financial gift of $\$ 4000$ would be paid into her bank account. What most impressed the employee was that this tangible material support was not given social prominence; it was not publicized by the organization but simply given.

The state government's flood response efforts impressed most of the interviewees. They were centered on providing material support to those affected. Shelters were set up for people to rest, shower, as well as receive blankets and food, across the region. The government issued grants of $\$ 1000$ per person to people from flood affected areas that were without electricity for at least 48 hours. Some interviewees found these grants wasteful, however, describing the initiative as "throwing cash at the problem", as many people who were not in need seemed to take advantage of the scheme. Not only the government responded in materially useful ways. Banks set up mobile units at shelters to cash these checks and provide hardship arrangements. Interviewees were full of praise for how quickly the government, local councils, and volunteers, restored key infrastructure. The emergence of 62,000 registered (along with an estimated 180,000 unregistered) volunteers armed with brooms and buckets, who helped the clean up effort, was one of the most inspiring media stories of the 
Brisbane floods (Bohensky \& Leitch, 2014). The then Brisbane Mayor, Campbell Newman, dubbed the volunteers a "mud army" while then Queensland State Premier Anna Bligh described the clean up effort as "operation compassion”.

\section{Fifth Process in the Unfolding Event: Supporting Others}

The fifth temporal process involved providing support to others. As predicted by emotional contagion theorists (Barger \& Grandey, 2006; Barsade, 2002; Hatfield, Cacioppo, \& Rapson, 1993; Pugh, 2001), the effects of receiving compassionate care during the Brisbane floods were contagious. In many cases, once people had received adequate support and were safe, they offered support to others. In some instances this involved organizations providing special discounts to flood affected customers, in other instances it involved donating to charity, providing physical household goods to people who had lost them, or helping with household clean up efforts. As an example, an interviewee who manages a restaurant in the Brisbane CBD recounted that while the floodwater came just one step away from flooding her home, others on her street were not so fortunate. As the floodwaters receded she was cleaning her home when an unknown woman knocked on her door and asked if there was any way she could help. The interviewee was so touched by this exchange that she decided she must help too. Observing others engaged in virtuous acts such as the providing of compassionate support (Lilius et al., 2012), can induce feelings of elevation or a desire to perform similar virtuous actions (Haidt, 2003). Using her vocation as a chef the interviewee went to a nearby supermarket and purchased food supplies, which she cooked at home. Piling the food on trays she took it take outside and served it to the volunteers involved in the clean up effort. Food is perhaps the most primordial sociomaterial comfort that can be provided to strangers, along with shelter. 


\section{Sixth Process in the Unfolding Event: Reconnecting}

While a critical event, such as a major flood, challenges people's sensemaking capabilities to affect cognition of its unfolding scope, much as a fire might engulf fire fighters (Weick, 1993) - but in slower motion - there comes a temporal moment of reckoning 'after' the event. The last process of 'reconnecting' relates to the sensemaking (Marshall \& Rollinson, 2004; Weick, 1995) and healing that occurred after the trauma of the flood had passed, after bonds had been forged through the experience of sharing struggling with crisis. Post-flood reconnecting and bonding occurred through talk between colleagues, discussions in an organization wide public forum, as well as through physical reconnections. Talking with co-workers or supervisors was important for employees struggling to make sense after the event. As well as seeking and providing comfort such talk began the process of healing and overcoming distress through talking resilience into existence (Beunza \& Stark, 2004). As an example, a female employee of the Queensland Government, described that on her first two days back at work she and her colleagues did more talking than working. Talking amongst colleagues provided an opportunity for employees to share fears, anxieties, and mourn their losses, as well as share relief and joy that things were not as bad as they could have been. Another interviewee explained that comparing experiences with colleagues invoked humility and gratitude and inspired her to make donations towards supporting colleagues and other flood victims who had not fared as well as she and her family. Talking, in other words, can be energizing and reinvigorating not only in normal (Gratton \& Ghoshal, 2002) but also in exceptional times. 
Another mode of reconnecting was through corporeal interactions. Research in nursing (Goodykoontz, 2007; Tutton, 1996), physical healing (Ford, 1999), crisis recovery (Justice, 2008), and childhood development (Heller, 1997), indicates appropriate culturally sensitive touch is an important mode of providing support and healing. Theoretically, with Yakhlef $(2010$, p. 410) we know that "the body is able to develop its own dispositions, habits and rules - most of which lie beyond reflection, conscious volition and social rules (Merleau-Ponty 1962; Bourdieu 1977).” As Barad (2003, p. 809) suggests, “the body's materiality — for example, its anatomy and physiology — and other material forces actively matter to the processes of materialization.” As corporeal responses to the Brisbane Flood crisis included physical symptoms of stress and panic such as tense muscles and tears, so compassion responding was also necessarily involved inter-corporeal relations. As an example, reassuring physical touch was sought and provided as hugging at all levels of organizational interactions; between junior, equal, and senior members of the organizational hierarchy. One interviewee who manages a dozen staff described that when she and her staff met again after being separated for several days, she greeted each of them with a hug. Similarly, another interviewee described being asked for a hug by a colleague at work who had suffered much material loss during the flood and who cried in her embrace.

\section{Discussion}

In this study we have emphasized organizational compassion as a sociomaterial process in which human-to-object relations play a significant role. Objects in human social environments do not just exist but are used for the fulfillment of certain objectives. In the context of the Brisbane floods sociomateriality was generally found 
to materialize compassion in a temporal rhythm of six processes involving communication technologies, organizational policy and resource availability, the immediacy of tangible artifacts, supporting others, and reconnecting through talk and corporeal interactions. While we describe our findings as six processes, their sequential materialization involved definite overlap and variability between organizations and interviewees. Consequently, although we observed sequences in the socio-materialization of compassion responding in our data, the findings cannot be generalized as infallible predictions applicable in all contexts. For example, the most significant event described by all interviewees was communication, yet even here we found variability. Some organizations pre-empted the flood to communicate care and send employees home to look after their families - in most cases these organizations had an ethic of caring for employees outside of the flood situation. In contrast, others were slow to communicate care even once the flood was in full flow. Still others communicated neglect, either through insensitive demands or through non-communication, which due to communication's autopoietic nature, is also a form of communication (Luhmann, 1992).

Variability was also found in the deviant cases of three managers amongst our 25 interviewees for whom communication was not the most significant initial compassion responding event. For them the initial process began by providing support to others, or dealing with policy issues to mobilize resources. We are hesitant to read too much into this, as another six managers in our dataset did describe communication as the most significant initial event. One conclusion might be that organizational compassion responding materializes in a different sequence for higherlevel managers empowered with decision-making authority. The significance of 
variability in activating resources to help materialize compassion is a question that can be pursued through further research.

Our findings have implications for ethical agency displayed through the morality of decision-making in compassion responding (or not). Agency lies not just with humans but also with material events and objects, as we argued at the outset. In doing so we were explicitly arguing against assumptions that materiality is ethically neutral whereas human behavior always displays an ethical register, either as good or harmful (Rundle \& Conley, 2007). According to such assumptions, material objects are neutral 'means' used instrumentally by human agents for the fulfillment of ethically relevant 'ends' (Barney, 2004). However, it is evident that political, social, environmental, economic, and other factors shape the design and production of material things (Stahl, 2003) such as a flood event, as well as the ethical choices managers make as they engage the material environment, for example, of whether to respond compassionately to a flood situation that affects employees home and work lives. Choices made by managers are shaped by the boundary conditions of material things but actors also shape matter in a recursive relationship (Aanestad, 2003). Consequently, managers are accountable in terms of the choices they make in their sociomaterial interactions. When material configurations cause harm it can be argued that there is an ethical responsibility to enact other sociomaterial configurations and materialize compassion to relieve the situation. We see this clearly in the data. The flood begins with decisions made by engineers; the flood itself is not a neutral instrumentality but an agent of destruction, displacement, confusion, and embodied anxiety; which media of communication is used concerning the flood event has a significant ethical impact on employees irrespective of the matter communicated; the objectivism and material implacability ascribed to bureaucracy's rules has a 
significant ethical impact; the comfort of strangers and the state in provisioning material wants has a significant ethical impact; the media's framing of the flood story in terms of images of graphic spectacle that were repetitively reiterated as dominant codes of tragedy representing the event had a significant ethical impact; the later use of the media to repeatedly communicate positive messages from authorities after explicit representations from organizational elites also had a significant ethical impact; expressing post-traumatic social relations through the materiality of bodily embrace and hugs has a significant ethical impact, embodying survival, experience and endurance of a sociomaterial process bonding them together more strongly than before. Each of these small elements of sociomateriality enmeshes compassion relations, the agency of things, people and organizations in an assemblage of processes that is difficult to disentangle into pristine categories of agency, ethics, society and nature. It is quite evident that material things, such as rolling news transmission, churning and swollen water and the comfort of strangers all had agency. It is equally evident that non-decisions to make the flood an issue, to act compassionately towards its effects, to presume that business as usual should not be abrogated also had agency.

Linking the published research on the many benefits of on organizational compassion (see reviews by Lilius et al., 2011; Rhee et al., 2007), with the findings of the current study, our sociomaterial analysis of interconnected agency also implies that an organization's capacity for compassion responding has the potential to increase (positive-sum) or reduce (zero-sum) the organization's total effectiveness (Simpson, Clegg, \& Freeder, 2013). If in times of crisis the organization struggles collectively and compassionately for the benefit of each part (including each employee), the whole recovers its equilibrium more quickly. Conversely, when 
separation is artificially imagined between the parts and the whole and processes of compassion responding are not materialized, overall, the whole is diminished.

Our study further implies that organizational compassion should not be limited to emotional or psychological modes of theorizing - it is much too complex for such limited perspectives. As a sociomaterial process it also crucially involves organization and management in shared agency with other sociomaterial actors, as seen everywhere in this study. Organization and management are explicit and takenfor-granted; they are enacted and sabotaged; they are embedded in rules and they are embedded in rule-breaking; they are implicit in routines and in the violation of routines; they configure leadership and lack of leadership; they embrace both forms of democratic and authoritarian inclusion; they are coded into broadcasting conceptions of news values and visual imagery; they are choices made and choices not made. Organizational compassion relations have no materiality outside of the situated actions, situated choices and situated events. The occurrence of catastrophic events can expose organizational pretensions to compassion that are not translated into practice. Compassion is not a state of being so much as a sociomaterial process, as the unfolding events analyzed herein demonstrate.

\section{Conclusion}

In this study we have analyzed the compassion responding of organizations in relation to their employees during and after the Brisbane floods January 2011. Our findings indicate that organizational compassion can be conceived as a temporally situated, social relational process in which materiality matters. We suggested, in summary, that compassion makes networks of human and non-human agency material. In this materialization, it is human agency that is held ethically accountable 
in terms of its propensity to "intervene in the world's becoming, to contest and rework what matters and what is excluded from mattering” (Barad, 2003, p. 827). The lesson for managers is that failure to acknowledge accountability, limits one's capacity to understand and to activate compassion. Suffering caused by events is a reality of organizational life that challenge organizational routines, transform modes of member engagement and give rise to unexpected contingencies. Events, whether natural, man-made or hybrid (as was the flood) pose circumstances in which the actions of significant others in acting towards those whom the events unfold and engulf will, contextually, be judged in terms of the extent to which, as significant others, they acted compassionately. 


\section{References}

Aanestad, M. (2003). The Camera as an Actor Design-in-Use of Telemedicine Infrastructure in Surgery. Computer Supported Cooperative Work, 12(1), 120 .

Abbott, A. (1995). Sequence analysis: new methods for old ideas. Annual Review of Sociology, 21, 93-113.

Abbott, A., \& Barman, E. (1997). Sequence comparison via alignment and Gibbs sampling: A formal analysis of the emergence of the modern sociological article. Sociological Methodology, 27(1), 47-87.

Abbott, A., \& Forrest, J. (1986). Optimal matching methods for historical sequences. Journal of Interdisciplinary History, 16(3), 471-494.

Abbott, A., \& Hrycak, A. (1990). Measuring resemblance in sequence data: An optimal matching analysis of musicians' careers. American Journal of Sociology, 96(1), 144-185.

Abbott, A., \& Tsay, A. (2000). Sequence analysis and optimal matching methods in sociology: Review and prospect. Sociological Methods \& Research, 29(1), 333.

Anheier, H., \& Katz, H. (2006). Learning from history? Comparative historical methods and researching global civil society. In M. Glasius, M. Kaldor \& H. Anheier (Eds.), Global civil society (pp. 288-304). London: Sage.

Ashforth, B. E., \& Humphreys, M. (1993). Emotional labor in service roles: The influence of identity. Academy of Management Review, 18(1), 88-115.

Barad, K. (2003). Posthumanist performativity: Toward an understanding of how matter comes to matter. Signs, 28(3), 801-831.

Barger, P. B., \& Grandey, A. A. (2006). Service with a smile and encounter satisfaction: Emotional contagion and appraisal mechanisms. Academy of Management Journal, 49(6), 1229-1238.

Barney, D. (2004). The network society. Cambridge: Polity.

Barsade, S. G. (2002). The ripple effect: Emotional contagion and Its influence on group behavior. Administrative Science Quarterly, 47(4), 644-677.

Berlant, L. (2004). Introduction: compassion (and withholding). In L. Berlant (Ed.), Compassion: The culture and politics of an emotion (pp. 1-13). New York: Routledge. 
Beunza, D., \& Stark, D. (2004). Survival and sensemaking: Organizational resilience in a Wall Street trading room after 9/11. Universitat Pompeu Fabra Economics and Business Working Paper(734).

Beunza, D., \& Stark, D. (2005). Resolving identities: Successive crises in a trading room after 9/11. In N. Foner (Ed.), Wounded city: The social impact of 9/11 (pp. 293-320). New York: Russell Sage Foundation.

Blair-Loy, M. (1999). Career Patterns of Executive Women in Finance: An Optimal Matching Analysis 1. American Journal of Sociology, 104(5), 1346-1397.

Bohensky, E. L., \& Leitch, A. M. (2014). Framing the flood: a media analysis of themes of resilience in the 2011 Brisbane flood. Regional Environmental Change, 14(2), 475-488.

Burdenski, H., \& Dunson, D. (1999). Acquiring economic justice for all: An ongoing struggle. Journal of Business Ethics, 20(2), 93-99.

Cameron, K., \& Winn, B. (2012). Virtuousness in organizations. In K. S. Cameron \& G. Spreitzer (Eds.), The Oxford Handbook of Positive Organizational Scholarship (pp. 231-243). Oxford: Oxford University Press.

Carah, N., \& Louw, E. (2012). Inundated by the audience: Journalism, audience participation and the 2011 Brisbane flood. Media International Australia, Incorporating Culture \& Policy, August 2012(144), 137-145.

Chan, T. W. (1995). Optimal matching analysis: A methodological note on studying career mobility. Work and Occupations, 22(4), 467-490.

Coombs, W. T. (1999). Information and compassion in crisis responses: A test of their effects. Journal of Public Relations Research, 11(2), 125-142.

Curtis, R. (2008). 'Katrina and the waves: bad organization, natural evil or the State. Culture and Organization, 14(2), 113-133.

Czarniawska, B. (2000). The uses of narrative in organization research rapport $n r$. 2000-5: GRI reports. Gothenburg, Sweden: Gothenburg Research Institute.

Czarniawska-Joerges, B. (2004). Narratives in social science research. London: Sage.

Davis, D. E., Worthington Jr, E. L., Hook, J. N., Emmons, R. A., Hill, P. C., Bollinger, R. A., \& Van Tongeren, D. R. (2013). Humility and the development and repair of social bonds: Two longitudinal studies. Self and Identity, 12(1), 58-77. 
Deleuze, G. (1990). Logique du sens, Paris: Éditions de Minuit, 1969; The Logic of Sense. Trans. Mark Lester and Charles Stivale. New York: Columbia University Press.

Deleuze, G. (1994). Difference and repetition (P. Patton, Trans.). London: Athlone.

Deleuze, G., \& Guattari, F. (1988). A thousand plateaus: Capitalism and schizophrenia (B. Massumi, Trans.). London: Athlone.

Deroy, X., \& Clegg, S. (2011). When events interact with business ethics. Organization, 18(5), 637-653.

Dutton, J. E., Frost, P., Worline, M. C., Lilius, J. M., \& Kanov, J. M. (2002). Leading in times of trauma. Harvard Business Review, 80(1), 54-61.

Dutton, J. E., Lilius, J. M., \& Kanov, J. M. (2007). The transformative potential of compassion at work. In S. K. Piderit, R. E. Fry \& D. L. Cooperrider (Eds.), Handbook of transformative cooperation: New designs and dynamics (pp. 107-124). Stanford: Stanford University Press.

Dutton, J. E., Workman, K. M., \& Hardin, A. E. (2014). Compassion at work. Annual Review of Organizational Psychology and Organizational Behavior, 1, 277 304.

Dutton, J. E., Worline, M. C., Frost, P. J., \& Lilius, J. (2006). Explaining compassion organizing. Administrative Science Quarterly, 51(1), 59-96.

Feldman, M. S. (2004). Resources in emerging structures and processes of change. Organization Science, 15(3), 295-309.

Fenwick, T. (2010). Re-thinking the "thing": Sociomaterial approaches to understanding and researching learning in work. Journal of Workplace Learning, 22(1/2), 104-116.

Ford, C. (1999). Compassionate Touch: The Body's Role in Emotional Healing and Recovery. Berkeley: North Atlantic Books.

Forrest, J., \& Abbott, A. (1990). The optimal matching method for studying anthropological sequence data: An introduction and reliability analysis. Journal of Quantitative Anthropology, 2(2), 151-170.

Frickel, S., \& Vincent, M. B. (2007). Hurricane Katrina, contamination, and the unintended organization of ignorance. Technology in Society, 29(2), 181-188.

Frost, P. J. (1999). Why compassion counts. Journal of Management Inquiry, 8(2), 127-133. 
Frost, P. J., Dutton, J. E., Worline, M. C., \& Wilson, A. (2000). Narratives of compassion in organizations. In S. Fineman (Ed.), Emotions in organizations (pp. 25-45). London: Sage.

Frost, P. J., \& Robinson, S. (1999). The toxic handler: organizational hero--and casualty. Harvard Business Review, 77(4), 96-106.

Garfinkel, H. (1967). Studies in ethnomethodology. Cambridge: Polity Press.

Giddens, A. (1982). Profiles and critiques in social theory. Berkeley, CA: University of California Press.

Giddens, A. (1984). The constitution of society: Outline of the theory of structuration. Berkeley: University of California Press.

Glaser, B. G., \& Strauss, A. L. (1967). The discovery of grounded theory: Strategies for qualitative research. Chicago: Aldine.

Goodykoontz, L. (2007). Touch: Attitudes and practice. Nursing Forum, 18(1), 4-17.

Grace, W. R., \& Fonseca, F. (2014). Adopting a sociomaterial perspective for the analysis of digital public spheres. iConference 2014 Proceedings, 791-797.

Gratton, L., \& Ghoshal, S. (2002). Improving the quality of conversations. Organizational Dynamics, 31(3), 209-223.

Griffin, L. J. (1993). Narrative, event-structure analysis, and causal interpretation in historical sociology. American Journal of Sociology, 98(5), 1094-1133.

Haidt, J. (2003). Elevation and the positive psychology of morality. In C. L. M. Keyes \& J. Haidt (Eds.), Flourishing: Positive psychology and the life welllived (pp. 275-289). Washington, D.C.: American Psychological Association.

Hatfield, E., Cacioppo, J. T., \& Rapson, R. L. (1993). Emotional contagion. Current Directions in Psychological Science, 2(3), 96-100.

Heller, S. (1997). The vital touch: How intimate contact with your baby leads to happier, healthier development. New York: Holt.

Henke, C. R. (2007). Situation normal? Repairing a risky ecology. Social studies of science, 37(1), 135-142.

Hochschild, A. R. (1979). Emotion work, feeling rules, and social structure. American Journal of Sociology, 85(3), 551-575.

Hochschild, A. R. (1983). The managed heart: the comercialization of human feeling. Berkley: University of California Press.

Holmes, C. E. (2011). Interum Report. Brisbane: Queensland Floods Commission of Inquiry. 
Insurance Council of Australia. (2011). Cost of 2011's catastrophies passes $\$ 4.3$ billion as builders take a break. Retrieved 21 December, from Insurance Council of Australia http://www.insurancecouncil.com.au/media_release/plain/57

Jarzabkowski, P., Spee, A., \& Smets, M. (2013). Material artifacts: Practices for doing strategy with 'stuff'. European Management Journal, 31(1), 41-54. Justice, P. (2008). The importance of touch and non-verbal communication in the recovery process: An intercultural prospective. Paper presented at the From Crisis to Recovery: Proceedings of the 6th Rocky Mountain Region Disaster Mental Health Conference.

Kanov, J. M., Maitlis, S., Worline, M. C., Dutton, J. E., Frost, P. J., \& Lilius, J. M. (2004). Compassion in organizational life. American Behavioral Scientist, 47(6), 808-827.

Langley, A. (1999). Strategies for theorizing from process data. Academy of Management Review, 24(4), 691-710.

Lawrence, T., \& Maitlis, S. (2012). Care and possibility: Enacting an ethic of care through narrative practice. Academy of Management Review, 37(4), 641-663.

Lilius, J. M., Kanov, J., Dutton, J. E., Worline, M. C., \& Maitlis, S. (2012). Compassion revealed: What we know about compassion at work (and where we need to know more). In K. S. Cameron \& G. Spreitzer (Eds.), The Oxford Handbook of Positive Organizational Scholarship (pp. 273-287). Oxford: Oxford University Press.

Lilius, J. M., Worline, M. C., Dutton, J. E., Kanov, J. M., \& Maitlis, S. (2011). Understanding compassion capability. Human Relations, 64(7), 873-899.

Lilius, J. M., Worline, M. C., Maitlis, S., Kanov, J. M., Dutton, J. E., \& Frost, P. J. (2008). The contours and consequences of compassion at work. Journal of Organizational Behavior, 29(2), 193-218.

Linstead, S., \& Thanem, T. (2007). Multiplicity, virtuality and organization: The contribution of Gilles Deleuze. Organization Studies, 28(10), 1483-1501. Luhmann, N. (1992). What is communication? Communication Theory, 2(3), 251259. 
Lynchnell, L. (2011). An event-based approach for the "intermediate step" in process studies of IT-related organizational change. Systems, Signs and Actions, 5, 8499.

Marshall, N., \& Rollinson, J. (2004). Maybe Bacon had a point: The politics of interpretation in collective sensemaking. British Journal of Management, 15(S1), S71-S86.

Mills, J. H., \& Weatherbee, T. G. (2006). Hurricanes hardly happen: Sensemaking as a framework for understanding organizational disasters. Culture and Organization, 12(3), 265-279.

Nussbaum, M. C. (2003). Upheavals of thought: The intelligence of emotions. Cambridge: Cambridge University Press.

Olofsson, J. K. (2010). Mass movements in computer-mediated environments: An account of crowds as socio-material densities. Information, Communication \& Society, 13(5), 765-784.

Orlikowski, W. J. (1992). The duality of technology: Rethinking the concept of technology in organizations. Organization Science, 3(3), 398-427.

Orlikowski, W. J. (2007). Sociomaterial practices: Exploring technology at work. Organization studies, 28(9), 1435-1448.

Orlikowski, W. J. (2008). Using technology and constituting structures: A practice lens for studying technology in organizations. Resources, Co-Evolution and Artifacts, 255-305.

Orlikowski, W. J. (2010). The sociomateriality of organizational life: considering technology in management research. Cambridge Journal of Economics, 34(1), 125-141.

Orlikowski, W. J., \& Scott, S. V. (2009). Sociomateriality: Challenging the separation of technology, work and organization. The Academy of Management Annals, 2(1), 433-474.

Perrow, C. (2011). Normal accidents: Living with high risk technologies: Princeton University Press.

Perry, M. (2007). Natural disaster management planning: a study of logistics managers responding to the tsunami. International Journal of Physical Distribution \& Logistics Management, 37(5), 409-433.

Pickering, A. (1995). The mangle of practice: Time, agency, and science. Chicago: University of Chicago Press. 
Pickering, A. (2008). New ontologies. In A. Pickering \& K. Guzik (Eds.), The mangle in practice: Science, society and becoming (pp. 1-14). Durham, NC: Duke University Press.

Piotrowski, C. (2006). Hurricane Katrina and Organization Development: Part 1. Implications of Chaos Theory. Organization Development Journal, 24(3).

Pugh, S. D. (2001). Service with a smile: Emotional contagion in the service encounter. Academy of Management Journal, 44(5), 1018-1027.

Rego, A., Cunha, M. P., \& Clegg, S. R. (2012). The virtues of leadership: Contemporary challenges for global managers. Oxford: Oxford University Press.

Rhee, S.-Y., Dutton, J. E., \& Bagozzi, R. P. (2007). Making sense of organizational actions with virtue frames and its links to organizational attachment. Journal of Management, Spirituality and Religion, 3(1 \& 2), 34-59.

Rundle, M., \& Conley, C. (2007). Ethical implications of emerging technologies: A survey. Paris: UNESCO.

Rynes, S., Bartunek, J., Dutton, J., \& Margolis, J. (2012). Care and compassion through an organizational lens: Opening up new possibilities. Academy of Management Review, 37(4), 503-523.

Sabherwal, R., \& Robey, D. (1993). An empirical taxonomy of implementation processes based on sequences of events in information system development. Organization Science, 4(4), 548-576.

Sabherwal, R., \& Robey, D. (1995). Reconciling variance and process strategies for studying information system development. Information Systems Research, 6(4), 303-327.

Silverman, D. (2006). Interpreting qualitative data: Methods for analyzing talk, text, and interaction. London: Sage.

Simpson, A. V., Clegg, S., \& Freeder, D. (2013). Power, compassion and organization. Journal of Political Power, 6(3), 385-404.

Simpson, A. V., Clegg, S., Lopez, M. P., Cunha, M. P., Rego, A., \& Pitsis, T. (2014). Doing compassion or doing discipline? Power relations and the Magdalene Laundries. Journal of Political Power, 7(2), 253-247.

Simpson, A. V., Clegg, S., \& Pitsis, T. (2014a). "I used to care but things have changed": A genealogy of compassion in organizational theory. Journal of Management Inquiry, 23(4), 347-359. 
Simpson, A. V., Clegg, S., \& Pitsis, T. (2014b). Normal compassion: A framework for compassionate decision making. Journal of Business Ethics, 119(4), 473491.

Solomon, R. C. (1998). The moral psychology of business: Care and compassion in the corporation. Business Ethics Quarterly, 8(3), 515-534.

Stahl, B. C. (2003). The moral and business value of information technology: what to do in case of a conflict? In N. Shin (Ed.), Creating business value with information technology: Challenges and solutions (pp. 187-202). Hershey, PA: IRM Press.

Strauss, A., \& Corbin, J. (1997). Grounded theory in practice. London: Sage.

Suchman, L. A. (2007). Human-machine reconfigurations: Plans and situated actions. Cambridge: Cambridge University Press.

Tutton, E. (1996). An exploration of touch and its use in nursing. In R. McMahon \& A. Pearson (Eds.), Nursing as therapy (2nd ed., pp. 169-200). Cheltenham, UK: Nelson Thorns.

van den Honert, R. C., \& McAneney, J. (2011). The 2011 Brisbane floods: causes, impacts and implications. Water, 3(4), 1149-1173.

van der Velden, M. (2009). Design for a common world: On ethical agency and cognitive justice. Ethics and Information Technology, 11(1), 37-47.

Veil, S. R., Buehner, T., \& Palenchar, M. J. (2011). A work-in-process literature review: Incorporating social media in risk and crisis communication. Journal of Contingencies and Crisis Management, 19(2), 110-122.

Weick, K. (1995). Sensemaking in organizations. Thousand Oaks, CA: Sage.

Weick, K. (2003). Positive organizing and organizational tragedy. In K. Cameron, J. Dutton \& R. E. Quinn (Eds.), Positive organizational scholarship: Foundations of a new discipline (pp. 66-80). San Francisco: Berrett-Koehler.

Weick, K. E. (1993). The collapse of sensemaking in organizations: The Mann Gulch disaster. Administrative Science Quarterly, 38(4), 628-652.

Weick, K. E., \& Westley, F. (1999). Affirming an Oxymoron. In S. R. Clegg, C. Hardy \& W. R. Nord (Eds.), Managing organizations: Current issues (pp. 190-208). London: Sage.

Wernerfelt, B. (2006). A resource-based view of the firm. Strategic Management Journal, 5(2), 171-180. 
White, J. (1999). Ethical comportment in organizations: A synthesis of the feminist ethic of care and the Buddhist ethic of compassion. International Journal of Value-Based Management, 12(2), 109-128.

Yakhlef, A. (2010). The corporeality of practice-based learning. Organization Studies, 31(4), 409-430. 
Table 1. Sequential processes and quality of organizational compassion responding

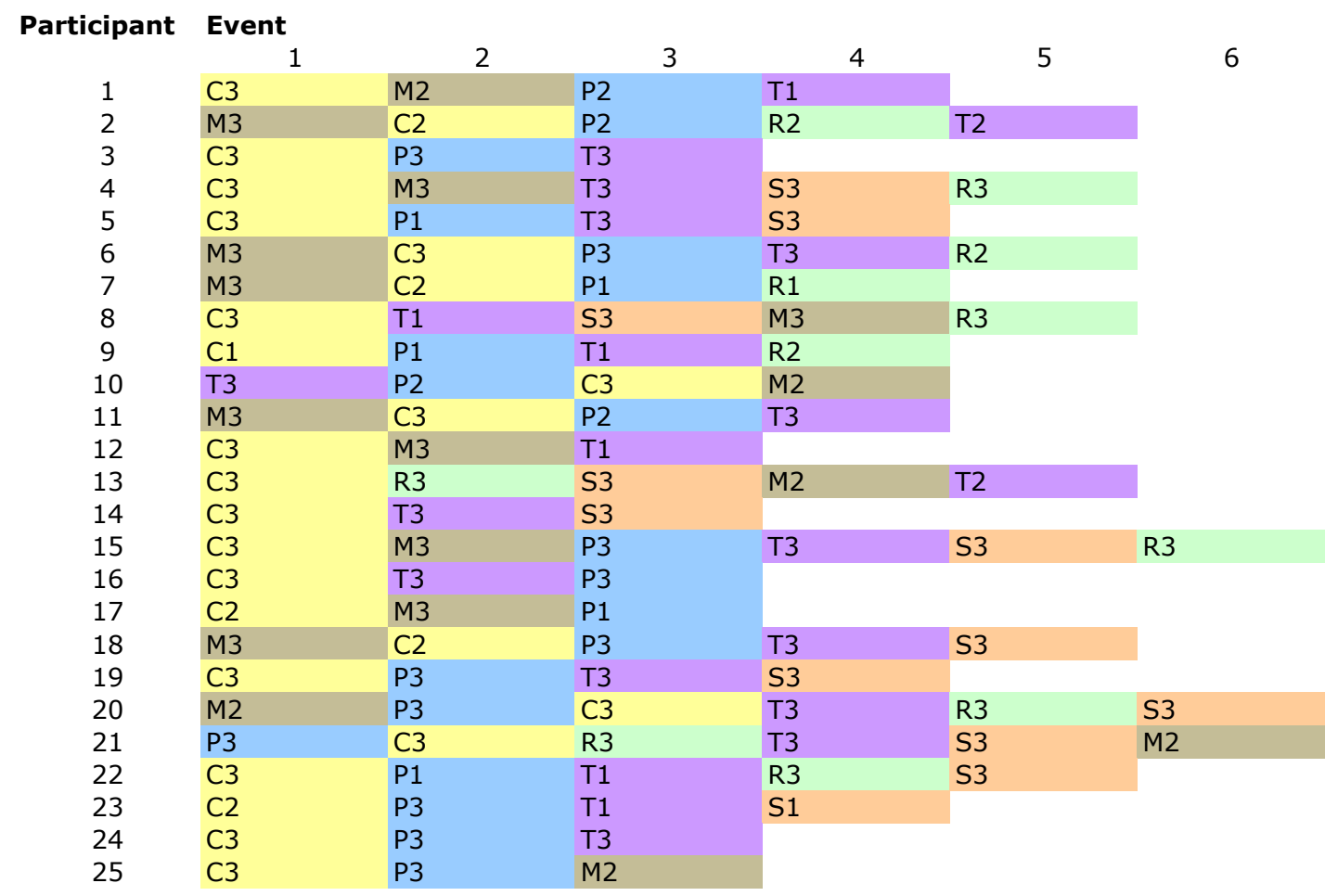

\section{Codes}

Communication

Fast

Delayed/poor

Minimal/None

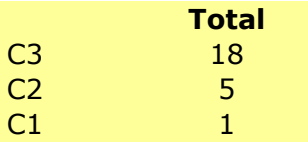

$\begin{array}{lcc}\text { Media } & & \text { Total } \\ \text { Neutral news } & \text { M3 } & 10 \\ \text { Negative news } & \text { M2 } & 5 \\ \text { Positive news } & \text { M1 } & 0\end{array}$

$\begin{array}{lcc}\text { Policy Decisions/Resources } & & \text { Total } \\ \text { Facilitated } & \text { P3 } & 10 \\ \text { Bending } & \text { P2 } & 4 \\ \text { Impeding } & \text { P1 } & 4\end{array}$

$\begin{array}{lcc}\text { Tangible } & & \text { Total } \\ \text { Provided pay/other } & \text { T3 } & 14 \\ \text { Delayed } & \text { T2 } & 2 \\ \text { Not provided } & \text { T1 } & 6\end{array}$

\begin{tabular}{lcc} 
Support others & & Total \\
Significant support & $\mathrm{S} 3$ & 11 \\
Minimal support & $\mathrm{S} 2$ & 0 \\
No support & $\mathrm{S} 1$ & 1 \\
\multicolumn{2}{l}{ Reconnect with work colleagues } & Total \\
Significant & $\mathrm{R} 3$ & 7 \\
Minimal & $\mathrm{R} 2$ & 3 \\
Non-event & $\mathrm{R} 1$ & 0
\end{tabular}

